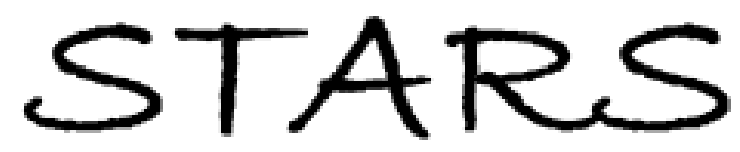

University of Central Florida

STARS

$1-1-2006$

\title{
Solvent effects on the three-photon absorption cross-section of a highly conjugated fluorene derivative
}

\author{
Ion Cohanoschi \\ University of Central Florida \\ Kevin D. Belfield \\ University of Central Florida \\ Carlos Toro \\ University of Central Florida \\ Florencio E. Hernández \\ University of Central Florida
}

Find similar works at: https://stars.library.ucf.edu/facultybib2000

University of Central Florida Libraries http://library.ucf.edu

This Article is brought to you for free and open access by the Faculty Bibliography at STARS. It has been accepted for inclusion in Faculty Bibliography 2000s by an authorized administrator of STARS. For more information, please contactSTARS@ucf.edu.

\section{Recommended Citation}

Cohanoschi, Ion; Belfield, Kevin D.; Toro, Carlos; and Hernández, Florencio E., "Solvent effects on the threephoton absorption cross-section of a highly conjugated fluorene derivative" (2006). Faculty Bibliography 2000s. 6038.

https://stars.library.ucf.edu/facultybib2000/6038

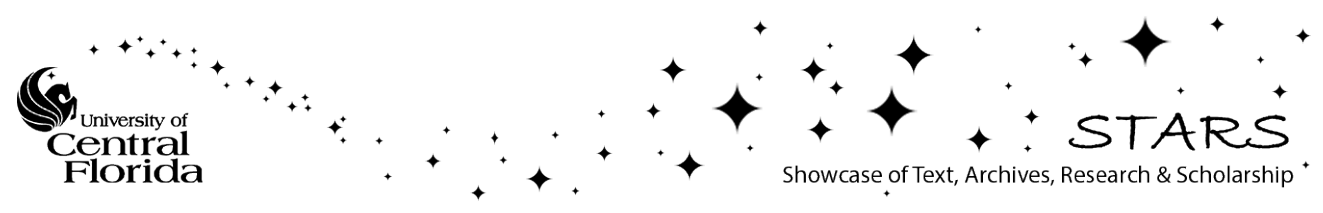




\section{Solvent effects on the three-photon absorption cross-section of a highly conjugated fluorene derivative}

Cite as: J. Chem. Phys. 125, 161102 (2006); https://doi.org/10.1063/1.2370750

Submitted: 30 August 2006 . Accepted: 25 September 2006 . Published Online: 30 October 2006

Ion Cohanoschi, Kevin D. Belfield, Carlos Toro, and Florencio E. Hernández

ARTICLES YOU MAY BE INTERESTED IN

Few-states models for three-photon absorption

The Journal of Chemical Physics 121, 2020 (2004); https://doi.org/10.1063/1.1767516

Three-photon absorption in anthracene-porphyrin-anthracene triads: A quantum-chemical study

The Journal of Chemical Physics 121, 11060 (2004); https://doi.org/10.1063/1.1813437

Structure-property relationships for three-photon absorption in stilbene-based dipolar and quadrupolar chromophores

The Journal of Chemical Physics 125, 044101 (2006); https://doi.org/10.1063/1.2216699

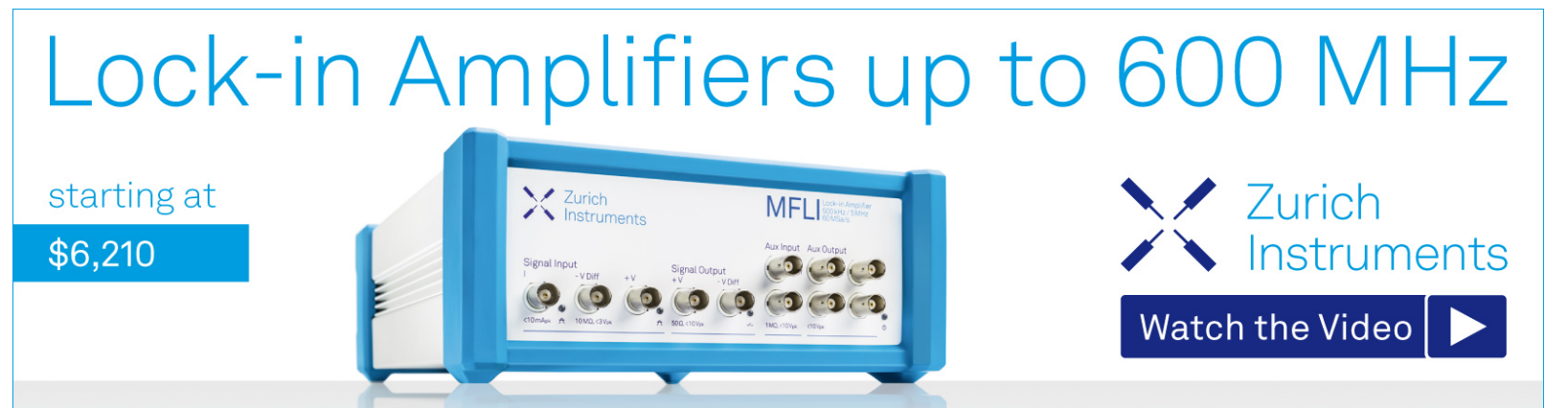

J. Chem. Phys. 125, 161102 (2006); https://doi.org/10.1063/1.2370750

125, 161102

(c) 2006 American Institute of Physics. 


\title{
Solvent effects on the three-photon absorption cross-section of a highly conjugated fluorene derivative
}

\author{
Ion Cohanoschi and Kevin D. Belfield \\ Department of Chemistry and CREOL, College of Optics \& Photonics, University of Central Florida, \\ Orlando, Florida 32816-2366 \\ Carlos Toro \\ Department of Chemistry, University of Central Florida, Orlando, Florida 32816-2366 \\ Florencio E. Hernández ${ }^{\text {a) }}$ \\ Department of Chemistry and CREOL, College of Optics \& Photonics, University of Central Florida, \\ Orlando, Florida 32816-2366
}

(Received 30 August 2006; accepted 25 September 2006; published online 30 October 2006)

\begin{abstract}
Herein, we report the study of the three-photon absorption cross-section dependence on

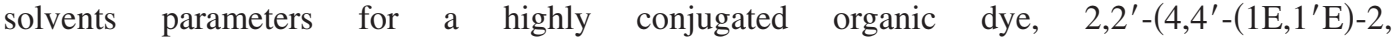
$2^{\prime}$-(9,9-didecyl-9H-fluorene-2,7-diyl) bis(ethene-2,1-diyl)bis(4,1-phenylene))dibenzo[d]thiazole (A- $\pi-\pi-\pi$-A). The three-photon absorption cross-section was measured for this organic dye in solution in four different solvents with polarity function, $\Delta f$ between 0.162 and 0.247 . The experiments show how the solvent's reorientation of the electrons and polarity contribute to the 3PA cross-section. Multiphoton-absorption experiments of A- $\pi-\pi$ - $\pi$-A in all four different solvents were performed with a tunable OPG pumped by a 25 picosecond Nd-YAG laser. (c) 2006 American
\end{abstract} Institute of Physics. [DOI: 10.1063/1.2370750]

\section{INTRODUCTION}

In the last ten years, three-photon absorption (3PA) processes have found many applications in optical limiting, ${ }^{1,2}$ fluorescence imaging, ${ }^{3-8}$ and stimulated emission. ${ }^{9}$ More recently, 3PA of organic molecules has attracted a lot of interest in the scientific community because of their potential applications in biomedicine and biotechnology. ${ }^{10}$ In organic molecules, 3PA typically occurs at long wavelengths in the near infrared region. Therefore, minimization of the scattered light losses is expected ${ }^{11}$ and, a reduction of the undesirable linear absorption in living organisms that present semitransparent windows at approximately 1100 and $1300 \mathrm{~nm}^{12}$ is anticipated. Consequently, the radiation penetration depth through tissue can be maximized, thus facilitating tumor imaging and photo-annihilation in the absence of risky surgery.

Several theoretical and experimental studies have addressed the effect of group symmetry, strength and conjugation of the donor and acceptor groups, and the length of $\pi$-electron delocalization on the 3PA cross-section $\left(\sigma_{3}^{\prime}\right)$ of organic materials. These studies have lead to developing new molecules with high 3PA. However, there is a lack of systematic studies on the solvent dependence for three-photon absorbing materials. In general, the 3PA cross-section of the organic compounds is determined in solution, often without regard to solvent polarity. Therefore, filling the existing gap in this field is essential for a better understanding of such an important nonlinear optical effect. In addition, comprehending this relationship could help predict the $\sigma_{3}^{\prime}$ optimum value of biocompatible molecules dissolved in water.

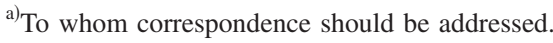

In this paper, we present the experimental study of the effects of reorientation of the electrons in the solvent (as a function of polarity) on the 3PA cross-section of 2 , $2^{\prime}$-(4,4'-(1E,1'E)- 2,2' -(9,9-didecyl-9H-fluorene-2,7-diyl) bis(ethene-2,1-diyl) bis(4,1-phenylene)) dibenzo[d]thiazole (A- $\pi-\pi-\pi-\mathrm{A})$.

\section{EXPERIMENTAL SECTION}

In order to understand solvent effects on the 3PA of organic molecules, full characterization of A- $\pi-\pi-\pi$-A in four different solvents (methyl benzoate, tetrahydrofuran (THF), acetophenone, and cyclohexanone) was carried out.

The synthesis of the highly conjugated fluorene derivative, $2,2^{\prime}$-(4,4' $-\left(1 \mathrm{E}, 1^{\prime} \mathrm{E}\right)-2,2^{\prime}$-(9,9-didecyl9H-fluorene-2,7-diyl)bis(ethene-2,1-diyl)bis(4,1-phenylene)) dibenzo[d]thiazole was reported in Ref. 13. The absorption spectra of the organic dye in all four solvents were recorded using an Agilent 8453 array UV-vis spectrometer (cell effects and solvent contributions were properly subtracted). These measurements were conducted in a $1 \mathrm{~mm}$ path length quartz cuvette filled with concentrations of ca. $10^{-5} \mathrm{M}$. The emission spectra were measured with an Ocean Optics USB2000 spectrometer using dye solutions at a concentration of $0.5 \times 10^{-3} \mathrm{M}$ in acetophenone and methyl benzoate, $1 \times 10^{-3} \mathrm{M}$ in THF, and $1.5 \times 10^{-3} \mathrm{M}$ in cyclohexanone.

The degenerate 3PA coefficient in each dye solution was measured using the well-known open-aperture Z-Scan technique. ${ }^{14}$ All measurements were performed using an EKSPLA 401 optical parametric generator (OPG) system pumped by a mode-locked, 25 ps EKSPLA PL-2143B laser [full width at half maximum (FWHM)], working at $10 \mathrm{~Hz}$ repetition rate. Experiments were performed using the same 

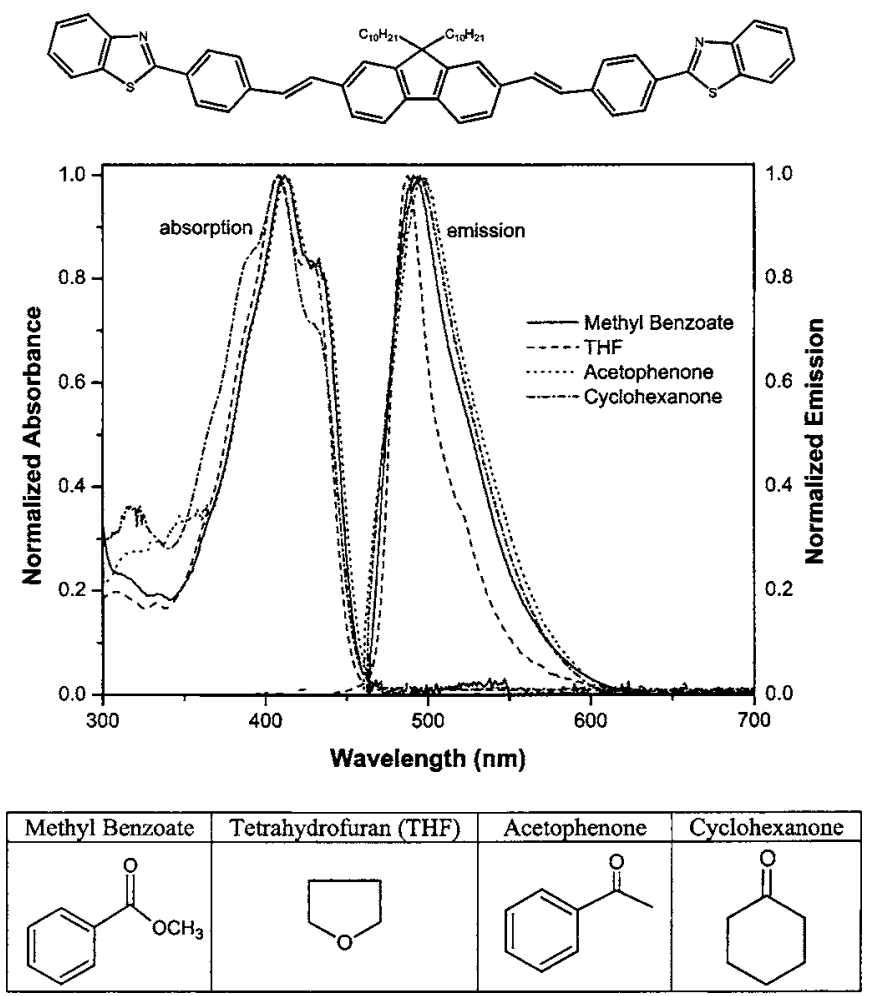

FIG. 1. Absorption spectra (left side) and emission spectra (right side) of A$\pi-\pi-\pi$-A dye in methyl benzoate (solid line), THF (dashed line), acetophenone (dotted line), and cyclohexanone (dash-dot line). Molecular structure of 2,2'-(4,4'-(1E, 1'E)-2,2'-(9,9-didecyl-9Hfluorene-2,7-diyl)bis(ethene-2,1-diyl)bis (4,1-phenylene))dibenzo[d]thiazole is shown on top of the figure. Bottom: Molecular structure of solvents.

setup as explained in Ref. 15. The peak value for 3PA was obtained at an excitation wavelength of $1230 \mathrm{~nm}$. Typical concentrations of A- $\pi-\pi-\pi$-A dye solution in solvents with different polarity were between $0.1 \times 10^{-3} \mathrm{M}$ and 1.5 $\times 10^{-3} \mathrm{M}$. Irradiances between 30 and $55 \mathrm{GW} / \mathrm{cm}^{2}$ were employed for 3PA measurements.

\section{RESULTS AND DISCUSSION}

Figure 1 shows the normalized absorption and emission spectra of A- $\pi-\pi-\pi$-A and, its molecular structure (top). The absorption and emission spectra depend only slightly on the polarity of the solvent. However, one can see a large Stoke's shift in all solvents. The relationship between the Stoke's shift $\left(\Delta \nu_{s}\right)$ and the solvent polarity $(\Delta f)$ is given by the Lippert-Mataga law: ${ }^{16}$

$$
\Delta \nu_{s}=\frac{2\left(\mu_{e}-\mu_{g}\right)^{2}}{h c a^{3}} \Delta f
$$

where $\mu_{e}$ and $\mu_{g}$ are the excited- and ground-state dipole moments, respectively, $h$ is the Plank's constant, $c$ is the speed of light and, $a$ is the cavity radius around the dye molecule. The Stoke's shift for methyl benzoate, THF, acetophenone and cyclohexanone, were 79, 80, 84, and $86 \mathrm{~nm}$, in that order. This well-known solvent effect on the fluorescence emission is due to the dipolar rearrangement of the solvent shell around the dye molecule in the excited state.

In order to determine the solvent effect on the 3PA crosssection open aperture, Z-scan experiments were performed on all samples. ${ }^{14}$ Figure 2 displays the experimental Z-scan curves (symbols) and their corresponding theoretical fittings (solid lines) for A- $\pi-\pi-\pi$-A in each solvent, taken at three different energies. The theoretical fittings were done employing the equations derived by Hernandez et al. ${ }^{17}$ for 3PA processes considering temporal and spatial Gaussian beam profiles. The corresponding 3PA coefficients were: $\alpha_{3 \text { (methyl benzoate) }}=(0.95 \pm 0.13) \times 10^{-21} \mathrm{~cm}^{3} \mathrm{~W}^{-2}, \quad \alpha_{3 \text { (THF) }}$ $=(1.18 \pm 0.2) \times 10^{-20} \mathrm{~cm}^{3} \mathrm{~W}^{-2}, \quad \alpha_{3 \text { (acetophenone })}=(2.56 \pm 0.36)$ $\times 10^{-21} \mathrm{~cm}^{3} \mathrm{~W}^{-2} \quad$ and $\quad \alpha_{3 \text { (cyclohexanone) }}=(6.0 \pm 0.95)$ $\times 10^{-22} \mathrm{~cm}^{3} \mathrm{~W}^{-2}$. Knowing the values of $\alpha_{3}$ in this series of solvents, we were able to obtain $\sigma_{3}^{\prime}$ using Eq. (2)

$$
\sigma_{3}^{\prime}=\frac{\alpha_{3}}{N_{A} d_{0} 10^{-3}}\left(\frac{h c}{\lambda}\right)^{2}
$$

Here, $N_{A}$ is the Avogadro's number, $d_{0}(\mathrm{~mol} / \mathrm{L})$ is the solution concentration, and $h c / \lambda$ is the energy of the incident photons. ${ }^{18}$ The experimental $\sigma_{3}^{\prime}$ values for the A- $\pi-\pi-\pi$-A in all solvents are shown in Table I, as well as the solvent dielectric constant $(\epsilon)$, refractive index $(n)$ and the polarity, which was determined as the orientation polarizability, $\Delta f$, given by Eq. (3). ${ }^{16}$

$$
\Delta f=\frac{\epsilon-1}{2 \epsilon+1}-\frac{n^{2}-1}{2 n^{2}+1}
$$

From Table I, one can remark the fact that as $\epsilon$ decreases $\sigma_{3}^{\prime}$ increases. The same trend was observed between $\Delta f$ and $\sigma_{3}^{\prime}$. Prasad and co-workers reported this tendency in studying the cooperative enhancement of 3PA in multibranched and dendritic structures. However, they claimed that this effect was due to mismatching in the optimum wavelength for the excitation of the chromophore in each solvent. ${ }^{19}$ In order to fairly compare $\sigma_{3}^{\prime}$ in different solvents, we excited at the optimum excitation wavelength of our dye in each solvent, i.e., $1230 \mathrm{~nm}$. To explain the observed behavior, we calculated the difference between the excited- and ground-state dipole moments of $\mathrm{A}-\pi-\pi-\pi-\mathrm{A}$ in all four different solvents using Eq. (1).

According to Cronstrand and co-workers, ${ }^{20,21}$ the 3PA probability based on a two-state model is proportional to the square of the matrix transition element, $T_{z z z}$.

$$
T_{\mathrm{ZZZ}}=27\left[\frac{\mu_{Z}^{0 f}\left\lfloor 2\left(\Delta \mu_{Z}\right)^{2}-\left(\mu_{Z}^{0 f}\right)^{2}\right\rfloor}{2 \omega_{f}^{2}}\right],
$$

As can be seen from Eq. (4) (Eq. (32) from Ref. 21), $T_{z z z}$ is directly proportional to $\left[\Delta \mu_{\text {Trans }}\left(\Delta \mu_{e g}^{2}-\Delta \mu_{\text {Trans }}^{2}\right)\right]$, where $\Delta \mu_{\text {Trans }}$ is the transition dipole moment. As a result, the 3PA cross-section, which is directly proportional to the 3PA probability, is expected to increase as $\Delta \mu_{e g}^{2}$ and $\Delta \mu_{\text {Trans }}$ increases. On the other hand, the authors state that for symmetric molecules, such as trans-stilbene, the sole term that contributes to the 3PA cross-section is $\Delta \mu_{\text {Trans }}$. However, for molecules like $\mathrm{A}-\pi-\pi-\pi$-A with symmetry point group $\mathrm{C}_{2 \nu}$ and a permanent dipole moment, both terms should be taken into account. If we consider, within a first approximation, that $\Delta \mu_{\text {Trans }}$ does not change much for A- $\pi-\pi-\pi$-A within our set of solvents, then the only term to be evaluated is $\Delta \mu_{e g}$. Our 

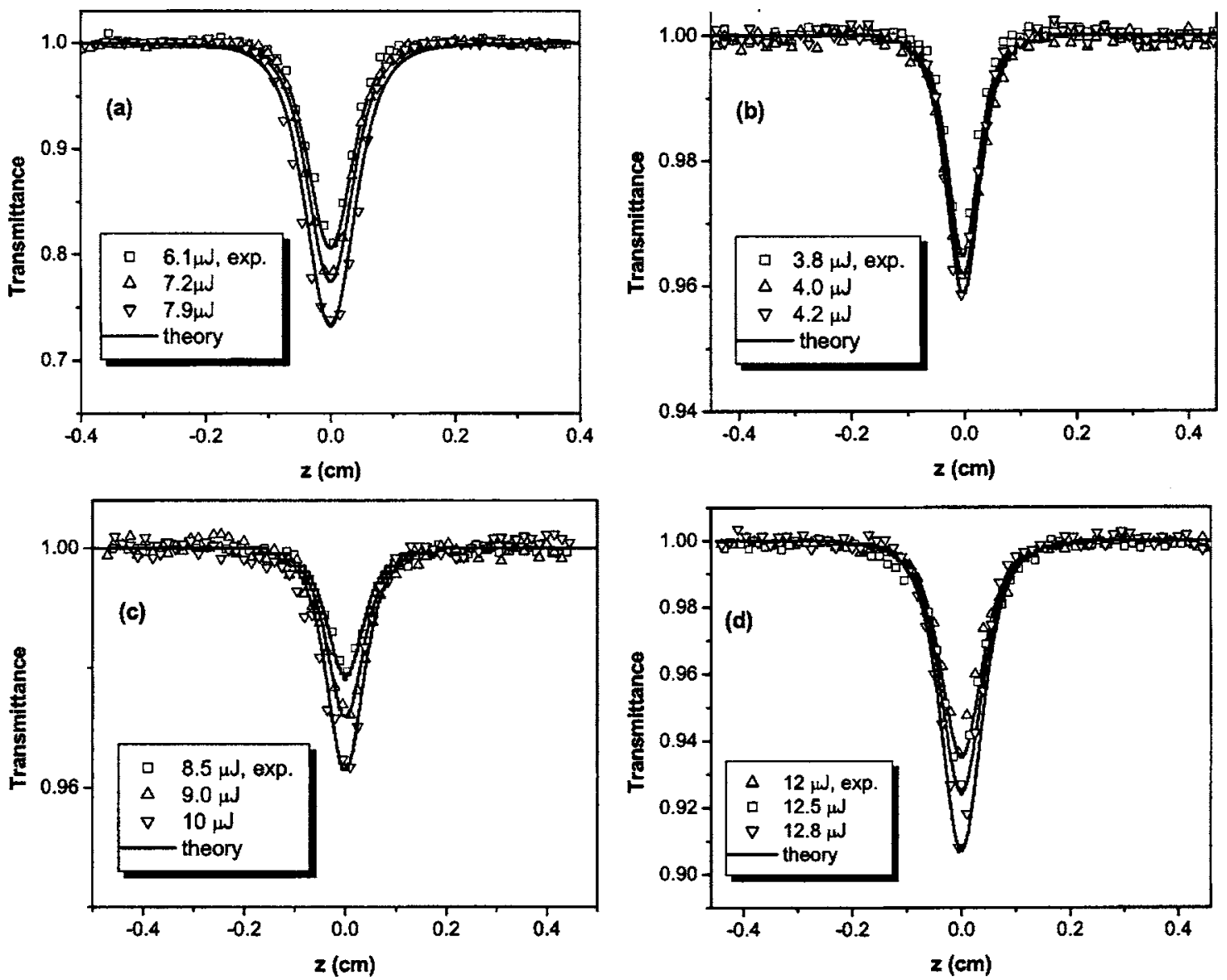

FIG. 2. Open aperture Z-scan measurements curves of A- $\pi$ - $\pi$ - $\pi$-A dye in: (a) THF $\left(1.0 \times 10^{-3} \mathrm{M}\right)$, (b) Acetophenone $\left(0.5 \times 10^{-3} \mathrm{M}\right)$, (c) Cyclohexanone $\left(0.25 \times 10^{-3} \mathrm{M}\right)$, and (d) Methyl Benzoate $\left(0.8 \times 10^{-4} \mathrm{M}\right)$. Solid curves are the theoretical fittings using the best-fit parameter $\alpha_{3}$ in the equation of nonlinear transmittance for three-photon absorption. We considered a Gaussian beam with a minimum waist of 13.75 microns and a wavelength of $1230 \mathrm{~nm}$.

approximation is valid since the difference in $\Delta f$ between the solvents is not greater than 1.5 fold.

In order to calculate $\Delta \mu_{e g}$ using Eq. (1), we made the following approximations. First, because the chosen solvent molecules are much smaller than A- $\pi-\pi-\pi$-A, $a$ can be virtually considered identical for all solvents. Second, because the Stoke's shifts in all four solvents are relatively similar, the only parameter that would determine the difference between the excited- and ground-state dipole moments is $\Delta f$. The estimated values of $\Delta \mu_{e g}^{2}$ shown in Table I are indeed greater for $\mathrm{A}-\pi-\pi-\pi$-A in solvents where $\sigma_{3}^{\prime}$ is greater and $\Delta f$ is smaller. Although, the difference in $\sigma_{3}^{\prime}$ between THF and acetophenone is not that remarkable, $\sigma_{3}^{\prime}$ in THF is still slightly greater than in acetophenone. This small difference may be explained by recognizing the importance of the transition dipole moment included in Eq. (32) ${ }^{21}$ and neglected in our assumption.

\section{CONCLUSIONS}

In summary, we have shown that the solvent polarity has a slight effect on the spectral shape and wavelength of absorption and fluorescence emission of the A- $\pi-\pi$ - $\pi$-A fluorene derivative. It has been experimentally demonstrated that the 3PA cross-section of this A- $\pi-\pi-\pi$-A molecule strongly depends on solvent polarity; the lower the polarity the larger the 3PA cross-section. Also, the higher the difference in $\Delta \mu_{e g}^{2}$ the higher the 3PA cross-section.

\section{ACKNOWLEDGMENTS}

This research was partially supported by start up funds provided to FEH by the Department of Chemistry, University of Central Florida. KDB would like to acknowledge the National Science Foundation (ECS-0524533 and DMR-

TABLE I. Three-photon absorption cross-section $\sigma_{3}^{\prime}\left(\mathrm{cm}^{6} \mathrm{~s}^{2} / \mathrm{ph}^{2}\right)$ of A- $\pi-\pi-\pi$-A in different solvents. Dielectric constant, refractive index and polarity of each solvent are also shown.

\begin{tabular}{lccccc}
\hline \hline Solvent & $\begin{array}{c}\text { Dielectric } \\
\text { constant }\end{array}$ & $\begin{array}{c}\text { Refractive } \\
\text { index }\end{array}$ & $\begin{array}{c}\left(\mu_{e}-\mu_{g}\right)^{2} / h c a^{3} \\
(\mathrm{~nm})\end{array}$ & $\begin{array}{c}\text { Polarity } \\
\Delta f\end{array}$ & $\begin{array}{c}\sigma_{3}^{\prime} / 10^{-78} \\
{\left[\mathrm{~cm}^{6} \mathrm{~s}^{2} / \mathrm{ph}^{2}\right]}\end{array}$ \\
\hline Methyl Benzoate & 6.6 & 1.516 & 243.8 & 0.162 & 544 \\
Tetrahydrofuran & 7.6 & 1.4052 & 190.5 & 0.21 & $511^{\mathrm{a}}$ \\
Acetophenone & 17.3 & 1.5372 & 189.7 & 0.22 & 218 \\
Cyclohexanone & 18.2 & 1.451 & 174.1 & 0.247 & 100 \\
\hline \hline
\end{tabular}


9975773) and the donors of The Petroleum Research Fund of the American Chemical Society for partial support of this work.

${ }^{1}$ G. S. He, J. D. Bhawalkar, and P. N. Prasad, Opt. Lett. 20, 1524 (1995).

${ }^{2}$ G. Zhou, X. Wang, D. Wang, Z. Shao, and M. Jiang, Appl. Opt. 41, 1120 (2000).

${ }^{3}$ M. Gu, Opt. Lett. 21, 988 (1996).

${ }^{4}$ S. W. Hell, K. Bahlmann, M. Schrader, A. Soini, H. Malak, I. Gryczynski, and J. R. Lakowicz, J. Biomed. Opt. 1, 71 (1996)

${ }^{5}$ J. R. Lakowicz, I. Gryczynski, H. Malak, M. Schrader, P. Engelhardt, H. Kano, and S. W. Hell, Biophys. J. 72, 567 (1997).

${ }^{6}$ H. Smacinski, I. Gryczynski, and J. R. Lakowicz, Biophys. J. 70, 547 (1996)

${ }^{7}$ S. Maiti, J. B. Shear, R. M. Williams, W. R. Zipfel, and W. W. Webb, Science 275, 530 (1997).

${ }^{8}$ R. Naskrecki, M. Menard, P. Van der Meulen, G. Vigneron, and S. Pommeret, Opt. Commun. 153, 32 (1998).

${ }^{9}$ G. S. He, P. P. Markowicz, T. Lin, and P. N. Prasad, Nature (London) 415, 767 (2002).

${ }^{10}$ W. Denk, J. H. Strickler, and W. W. Webb, Science 248, 73 (1990).

${ }^{11}$ R. W. Boyd (Ed.), Nonlinear Optics, Academic Press, San Diego, CA,
1992 (Chapt. 4 and 8).

${ }^{12}$ E. M. Attas, M. G. Sova, T. B. Posthumus, B. J. Schattka, H. H. Mantsch, and S. L. L. Zhang, Biopolymers 67, 96 (2002).

${ }^{13}$ K. D. Belfield, A. R. Morales, B.-S. Kang, J. M. Hales, D. J. Hagan, E. W. Van Stryland, V. M. Chapela, and J. Percino, Chem. Mater. 16, 4634 (2004).

${ }^{14}$ M. Sheik-Bahae, A. A. Said, T. Wei, D. J. Hagan, and E. W. Van Stryland, IEEE J. Quantum Electron. 26, 760 (1990).

${ }^{15}$ I. Cohanoschi, K. D. Belfield, C. Toro, S. Yao, and F. E. Hernandez, J. Chem. Phys. 124, 194707 (2006).

${ }^{16}$ J. Lakowicz, "Principles of Fluorescence Spectroscopy," John Wiley \& Sons, New York, 1999.

${ }^{17}$ F. E. Hernandez, K. D. Belfield, and I. Cohanoschi, Chem. Phys. Lett. 391, 22 (2004).

${ }^{18}$ R. Patell, F. Pradere, J. Hanus, M. Schott, and H. Puthoff, J. Chem. Phys. 46, 3507 (1967).

${ }^{19}$ Q. Zheng, G. S. He, A. Baev, and P. N. Prasad, J. Phys. Chem. B 110, 14604 (2006).

${ }^{20}$ P. Cronstrand, Y. Luo, P. Norman, and H. Agren, Chem. Phys. Lett. 375, 233 (2003).

${ }^{21}$ P. Cronstrand, P. Norman, Y. Luo, and H. Agren, J. Chem. Phys. 121, 2020 (2004) 